\title{
Physical activity in older age: perspectives for healthy ageing and frailty
}

\author{
Jamie S. McPhee - David P. French • \\ Dean Jackson • James Nazroo • \\ Neil Pendleton $\cdot$ Hans Degens
}

Received: 13 July 2015/Accepted: 19 February 2016/Published online: 2 March 2016

(C) The Author(s) 2016. This article is published with open access at Springerlink.com

\begin{abstract}
Regular physical activity helps to improve physical and mental functions as well as reverse some effects of chronic disease to keep older people mobile and independent. Despite the highly publicised benefits of physical activity, the overwhelming majority of older people in the United Kingdom do not meet the minimum physical activity levels needed to maintain health. The sedentary lifestyles that predominate in older age results in premature onset of ill health, disease and frailty. Local authorities have a responsibility to promote physical
\end{abstract}

J. S. McPhee $(\varangle) \cdot$ H. Degens

School of Healthcare Science, Manchester Metropolitan University, John Dalton Building, Manchester M1 5GD, UK

e-mail: j.s.mcphee@mmu.ac.uk

D. P. French

School of Psychological Sciences, University of

Manchester, Manchester, UK

D. Jackson

Faculty of Life Sciences, University of Manchester,

Michael Smith Building, Manchester, UK

J. Nazroo

School of Social Sciences, Humanities, University of

Manchester, Manchester, UK

N. Pendleton

Clinical Gerontology, Salford Royal Hospital \&

University of Manchester, Manchester, UK

H. Degens

Lithuanian Sports University, Kaunas, Lithuania activity amongst older people, but knowing how to stimulate regular activity at the population-level is challenging. The physiological rationale for physical activity, risks of adverse events, societal and psychological factors are discussed with a view to inform public health initiatives for the relatively healthy older person as well as those with physical frailty. The evidence shows that regular physical activity is safe for healthy and for frail older people and the risks of developing major cardiovascular and metabolic diseases, obesity, falls, cognitive impairments, osteoporosis and muscular weakness are decreased by regularly completing activities ranging from low intensity walking through to more vigorous sports and resistance exercises. Yet, participation in physical activities remains low amongst older adults, particularly those living in less affluent areas. Older people may be encouraged to increase their activities if influenced by clinicians, family or friends, keeping costs low and enjoyment high, facilitating group-based activities and raising self-efficacy for exercise.

Keywords Exercise - Physical activity - Muscle · Falls $\cdot$ Health $\cdot$ Frailty

\section{Background}

Data from the UK Office for National Statistics (2012) project an increase in the population aged over 60 years from $17 \%$ in 2010 to around $23 \%$ by 
2035. The most rapid rise is projected for the 'oldest' old, where the number of people aged over 85 years increases from 1.4 million to around 3.5 million. A general schematic representation of ageing is shown in Fig. 1. After the age of around 40 years it is possible to detect deterioration of the function of physiological systems, with associated anatomical and ultrastructural changes. For instance, progressive cognitive declines affect memory and learning; skeletal muscle atrophies and becomes progressively weaker (known as sarcopenia) and ageing-related declines in bone mineral density lead to osteopenia and osteoporosis. Chronological age is a convenient and often very good predictor of health status, disease burden and physical capability, but there is considerable inter-individual variability, with some older people having very good health and others show accelerated onset of weakness, disability and frailty.

The lifestyle and medical advances that contribute to longevity are achievements to celebrate, but they also bring unintended and considerable social, economic and health challenges as life expectancy increases faster than the period of life spent in good health, termed 'healthy life years' (discussed in (Rechel et al. 2013)). For instance, in the UK the mean life expectancy for women at birth in 2008 was 81.8 and in men it was 77.7 years and by 2013 this had increased to 82.9 for women and 79.2 years for men. Over this same time period, the mean healthy life expectancy had changed little, or even decreased: for women in 2008 it was 66.3 and in men it was 65 years, but by 2013 it had fallen to 64.8 in women and 64.4 years in men (Eurostat 2015). Musculoskeletal disorders are the most common chronic, disabling conditions, affecting $14 \%$ of people aged over 65 years. These are followed by heart and circulatory conditions affecting $10 \%$; respiratory conditions affecting $6 \%$; endocrine or metabolic conditions affecting $6 \%$ and mental disorders affecting $4 \%$ of people aged over 65 years. Incidence of these chronic diseases more than doubles in the 10 years that follow retirement. Of people aged over 75 years, $30 \%$ report chronic musculoskeletal conditions; $32 \%$ report heart and circulatory conditions and $13 \%$ report endocrine or metabolic conditions (ONS 2013). Another of the concerns is that the 'old age dependency ratio' will change from four working-age persons for every one older retired person, to just two working-age persons for every one older retired person in Europe (Eurostat 2014). This change in the ratio of workforce to the overall population may strain economic, social and healthcare support systems, so it is important to implement strategies to improve the health of older people.

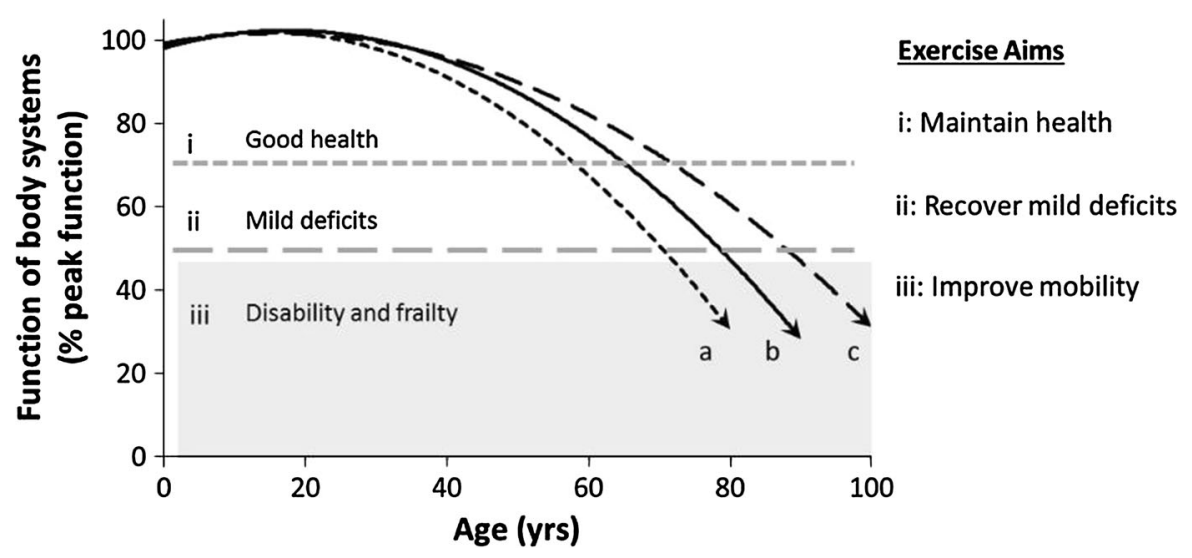

Fig. 1 Schematic representation of ageing trajectories and individual exercise needs. Good physiological function is maintained until middle age and thereafter progressively deteriorates. The upper horizontal dashed line represents a theoretical point at which deterioration manifests as moderate functional deficits and above this line the general aim of physical activity is to maintain good health. The lower horizontal dashed line indicates a theoretical threshold beyond which a person suffers disability and frailty, so the aim of physical activity is to recover the deficits and improve mobility. The curved lines represent $a$ accelerated ageing, $b$ normal ageing and $c$ healthy ageing. Exercise interventions should match the physical capability, rather than chronological age per se to be effective 


\section{Healthy ageing and frailty}

Healthy ageing has been defined as an ability to lead a healthy, socially inclusive lifestyle relatively free from illness or disability (age UK 2010), and this is more likely in those actively engaging in activities to improve their health and wellbeing (age UK 2015). Such people were recruited into the MYOAGE study (McPhee et al. 2013) and it was clear that despite no obvious difficulties with usual activities of daily living, the vast majority of older people aged in their $70 \mathrm{~s}$ had lower physiological function than young adults. For example, older adults had higher body mass index due to increased fatness, smaller and weaker muscles particularly in the legs, lower bone mineral density, reduced cardiorespiratory and metabolic function and performed worse in cognitive tests than young (Bijlsma et al. 2013a, b; Sillanpaa et al. 2014). Other studies have shown 30-50\% fewer motor neurons innervating leg muscles of healthy old compared with young, suggesting that motor unit remodelling is a part of the normal ageing process (Campbell et al. 1973; Piasecki et al. 2015a, b). The motor neuron and muscle fibre (Lexell et al. 1988) losses occurring during ageing can never be replaced, but the structure and function of cardiorespiratory, metabolic and musculoskeletal systems are amenable to improvement through exercise training, so it is informative to profile very athletic older people (master athletes). Master Athletes regularly compete in sports and demonstrate exceptional physical capability for their age (Rittweger et al. 2009). They usually retain greater bone, muscle, cardiorespiratory, metabolic and neuronal health compared with nonathletic people of similar age, but it is nevertheless evident that physiological systems decline in older age even in those who remain exceptionally active (Degens et al. 2013a, b; Ireland et al. 2014; Michaelis et al. 2008; Pearson et al. 2002; Power et al. 2010; Trappe et al. 2013; Wilks et al. 2009).

The progressive declines in physiological function that usually occur over decades are associated with slower walking speed and difficulties rising from a seated position and balancing. Standardised assessments have been developed to indicate physical capability in older age, including the 6-min walk (Rikli and Jones 1998) and the $30 \mathrm{~s}$ chair-rise test (Jones et al. 1999). The Short Physical Performance Battery assesses normal walking speed over $4 \mathrm{~m}$, balancing in different foot positions and time to complete 5 chair-rises, and the maximum score of 12 is easily achieved by healthy older people, while a score less than 8 indicates sarcopenia and frailty (Pahor et al. 2006). Thus, a score of between 8 and 11 indicates the moderate physical impairments associated with sarcopenia (low muscle mass) and 'prefrailty' (Bauer 2015). The Timed Up and Go (TUG) test involves standing from a seated position, walking around a cone placed 3 metres away and returning to a seated position on the original chair. Healthy men and women complete the task within $7 \mathrm{~s}$ (Bijlsma et al. 2013a) and frail people take $>10 \mathrm{~s}$ (British Geriatric Society 2014), suggesting that a score between 7-10 s is indicative of pre-frailty.

Frailty is recognised clinically as a geriatric syndrome that arises due to multiple deficits to body systems. Frail people experience severe impairments to physical and mental function that restrict their ability to complete necessary activities of daily living. Frailty is usually diagnosed according to two classifications. The Rockwood scale describes frailty as an accumulation of 'deficits', including the number of medications taken, number of diseases, frequency of medical interventions and other psychosocial indicators (Rockwood et al. 2005). The Fried Frailty Phenotype recognises frailty in people presenting at least three of the following five conditions: unintentional weight loss; low physical activity levels; slow gait speed; exhaustion, and weakness (Fried et al. 2001). Around $10 \%$ of people aged 65-75 years and half of all people aged over 80 years suffer from frailty, which is aggravated by a lower social status, comorbidities, medication use and lowered immunity (Ashfield et al. 2010; Clegg et al. 2013; Syddall et al. 2010; Yao et al. 2011). There is a wide spectrum of frailty, but typically, frail people have low physical activity, few social interactions as well as several chronic diseases that require medical attention (Marengoni et al. 2011). They are vulnerable to falling and may not fully recover from mild stressors or illness. Frailty can be a dynamic state, as some people with high levels of dependency or disability can recover independence, although they remain at higher risk of future mobility limitations than those who were never frail (Gill et al. 2006; Hardy and Gill 2004). Some recommended indicators of frailty are shown in Table 1, which are possible predictors of future falls (Ganz et al. 2007). 


\section{Regular physical activity to promote healthy ageing}

In general, the more often a person is physically active, the better their physical capability. This is due to adaptations of physiological systems, most notably within the neuromuscular system to coordinate movements, the cardiopulmonary system to more effectively distribute oxygen and nutrients around the body, and metabolic processes particularly those regulating glucose and fatty acid metabolism, which collectively increase overall aerobic power and physical capability. Thus, the trajectory towards frailty is directly modifiable through physical activity habits (Department of Health 2011; Health 2009; Tak et al. 2013).

A survey of $>92,000$ people in England showed that exercise participation declines progressively throughout adult life and so does the desire to participate (Department for Culture 2011). Indeed, only around half of all adults and just a quarter of people aged over 65 years meet the minimum recommended activity levels needed to maintain health (Department of Health 2011). Inactivity is the major cause of poor physiological fitness and disease in older age, at least equal to the effects of smoking, drinking excessive alcohol intake and obesity (Booth et al. 2000; Lee et al. 2012). Sedentary people aged 50 years and older had twice the risk of death compared with those who had the highest level of physical activity after adjusting for a range of risk factors (including age and socio-economic position) (Nazroo et al. 2008). For example, those who retire from work are more likely than those who remain in work to change to low levels of physical activity from both high and medium levels (Matthews et al. 2014) and people aged 70-79 years are about half as likely as those aged 50 to 59 years to be engaged in high levels of physical activity (Matthews et al. 2014). People aged $>80$ years are over $50 \%$ less likely than those in their early $50 \mathrm{~s}$ to engage in sports or to want to increase their activity levels (Fig. 2).

People with higher activity levels and physiological fitness have a lower mortality risk (Feldman et al. 2015). Maintenance of a physically active lifestyle through middle and older age is associated with better health in old age (Hamer et al. 2014) and longevity (Manini et al. 2006; Stessman et al. 2009). Beginning a new exercise regimen in middle age is associated with healthy ageing (Sabia et al. 2012; Sun et al. 2010). But, even for those who were relatively sedentary through middle age, it is never too late because beginning a new exercise regimen in old age leads to significant improvements to health (Berk et al. 2006; Hamer et al. 2014) and cognition (Lautenschlager et al. 2008). Physical activity reduces the risk of developing cardiovascular and metabolic disease through better control of blood

Table 1 Indicators of physical frailty and their measurement

\begin{tabular}{lll}
\hline Indicator & Measurement & Reference \\
\hline Walking & $<0.8 \mathrm{~m} / \mathrm{s}$ or taking more than 5 s to walk $4 \mathrm{~m}$ & BGS (2014) \\
& Inability to walk half-a-mile or negotiate stairs & Dufour et al. (2013) \\
Standing & $>10 \mathrm{~s}$ in the 'timed up and go' test & BGS (2014) \\
& $>30 \mathrm{~s}$ to complete $5 \times$ chair rise & Sallinen et al. (2010) \\
Muscle strength and power & Men grip strength: $<37 \mathrm{~kg}$ & Runge et al. (2004) \\
& Women grip strength: $<21 \mathrm{~kg}$ & \\
Balance & Standing jump $<8 \mathrm{~cm}$ & Dufour et al. (2013) \\
Activities of daily living & $<10 \mathrm{~s}$ standing on one leg & Fried et al. (2001) \\
& Difficulties to complete heavy housework & Daniels et al. (2008) \\
Self-reported health & Sedentary lifestyle and social isolation & BGS (2014)
\end{tabular}

Cut-off values indicate the level of physical functioning and health status 


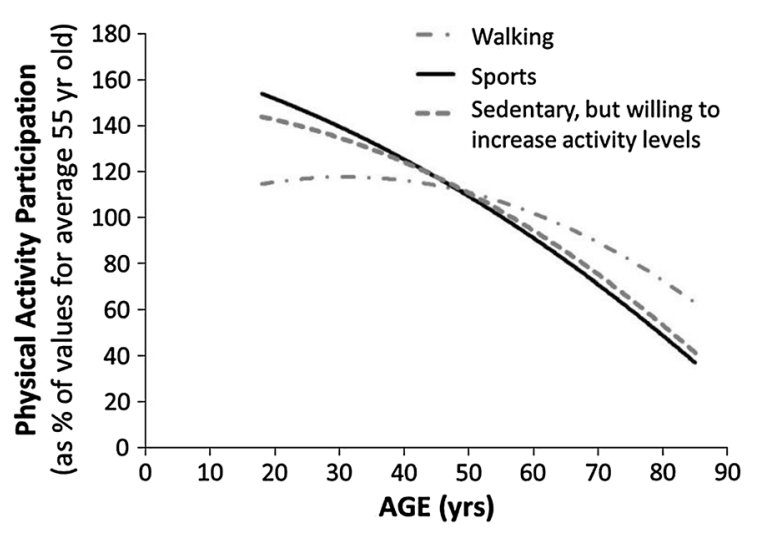

Fig. 2 Physical Activity Participation in UK adults. With increasing age, sports participation progressively declines. Walking for health benefits or enjoyment remains fairly constant amongst young and middle-aged adults, but declines progressively into older age. Amongst those who are sedentary, more of the younger adults have a desire to increase physical activity levels compared with the middle-aged and the old. Data are from The Taking Part Survey, which interviewed $>92,000$ people in England between 2005 and 2009 to ask about physical activity habits (Department for Culture 2011)

pressure, cholesterol and waist circumference in a dosedependent manner: more activity leads to lower risk of cardiovascular and metabolic disease (Earnest et al. 2013). The metabolic benefits of increasing fatty acid oxidation in skeletal muscle, rather than accumulating intramuscular and adipose tissue stores around the major organs as well as lowered blood pressure helps to reduce the risk of developing type 2 diabetes mellitus and cardiovascular disease (Roberts et al. 2013; Stewart et al. 2005). In the nervous system, regular exercise helps to maintain cognitive function (Lautenschlager et al. 2008) and possibly also the numbers of peripheral motor neurons controlling leg muscles (Power et al. 2010, 2012) and overall improves balance and coordination to reduce risk of falls (Franco et al. 2014; Gillespie et al. 2012; Rubenstein et al. 2000). Should a fall occur, people who exercise regularly (particularly weight bearing activities that include higher impacts) are less likely to suffer a bone fracture because their bones are stronger and have higher bone mineral density (Ireland et al. 2014).

\section{The general aims of physical activity programmes}

The National Institute for Health and Care Excellence recommend exercise as primary care (NICE 2009), but knowing how to encourage exercise participation at the population-level is challenging because a one-sizefits-all programme is not suitable. The intensity of exercise should be modified to appropriately match the individual's exercise experience and physical capability, as indicated in Fig. 1. To be most effective, it is important that exercise programmes are appropriately designed and focus on a range of outcomes, not simply weight loss, as improved health and mobility in exercising older people can occur independently of changes to body mass index (Bruce et al. 2008). Achieving $>150 \mathrm{~min} /$ week moderate-intensity aerobic exercise, such as walking or other moderate intensity aerobics-type activities, is associated with at least $30 \%$ lower risk of morbidity, mortality and functional dependence compared with being inactive (Chou et al. 2014; Paterson and Warburton 2010). Walking 5-7 days per week was associated with 50-80\% lower risk of mobility impairments (Clark 1996; Roh and Park 2013) and increases longevity by around 4 years and disability-free life expectancy by around two years (Ferrucci et al. 1999). There is also evidence that sedentary people will benefit from regular short activity periods of as little as $1 \mathrm{~min}$ (Healy et al. 2008) or $10 \mathrm{~min}$ bouts (Powell et al. 2011) to break-up periods of sitting or lying.

Although vigorous activities are not advisable for sedentary older people, masters athletes can train and compete in very high intensity sports, with the risks of adverse events during competition being similar to those of younger adults (Ganse et al. 2014). Older people who maintained regular jogging postponed disability by almost 9 years and had three times lower risk of death compared to those who had never been a member of a running club (Wang et al. 2002). The risk of developing cardiovascular disease is also lower in those completing regular vigorous compared with moderate intensity exercise (Swain and Franklin 2006). Thus, there appears to be a dose-response relationship to indicate that higher intensity activities bring greater health benefits (Bruce et al. 2008; Ebrahim et al. 2000; Kim et al. 2013; Wannamethee et al. 2005), but it is important to note that older people must be suitably adapted to participate in the higher intensity activities, so this relationship might reflect the overall exercise history.

It is advisable for older people to perform activities aimed at increasing the size and strength of their limb muscles in order to combat the effects of sarcopenia, 
the loss of muscle mass with ageing (Maden-Wilkinson et al. 2013; Rosenberg 1997). Moderate and high intensity strength training (using a resistance of between $60-80 \%$ of the maximal strength) increase muscle size, strength and power, even in very elderly and frail people (Fiatarone et al. 1990; Harridge et al. 1999). This is important since low muscle mass and power are associated with mobility impairments in older age (Dufour et al. 2013; Maden-Wilkinson et al. 2014). There is a dose-response relationship, meaning that higher intensity activities tend to lead to greater gains in muscle mass, strength and power than lower intensity activities (Steib et al. 2010). An expectation may be that gains in strength and power will improve walking, chair rising and stair negotiation, but several studies failed to confirm this (Beijersbergen et al. 2013; Paterson and Warburton 2010; Steib et al. 2010). However, the majority of resistance training studies were designed to target the muscles of the thigh and upper body, so the common tests of mobility might not be sensitive to show the effects on overall mobility. It is also important to train the ankle plantar flexors (calf muscles) since loss of power in this muscle group is associated with slower walking speed (Beijersbergen et al. 2013; Stenroth et al. 2015), and increased power with training improves balance (Orr et al. 2006) and mobility (Pereira et al. 2012).

Activities for frail older people should be adapted accordingly. Reviews of the literature (Forster et al. 2010; Weening-Dijksterhuis et al. 2011) led to the recommendations that frail older people should perform moderate-intensity leg-strengthening exercises and functional training, including walking, chair rising, balancing and game-like activities, two to three times per week with sessions lasting around $45 \mathrm{~min}$. This is in line with the suggestion that combined resistance and endurance training may be more beneficial than any of these exercise types individually for improving functional mobility, walking, balance, reducing falls risk and risk of developing metabolic and cardiovascular disease among older people with moderate deficits or frailty (Buchner et al. 1997; Davidson et al. 2009). The combination of strength and endurance training improved muscle, cardiorespiratory and metabolic health which all contributed to improved quality of life (Chin et al. 2004, 2006; Holviala et al. 2012; Sillanpaa et al. 2008, 2012). In men and women aged 70-89 years who were sedentary, but with moderate deficits and at high risk of disability, a 12-month combined training programme improved mobility significantly more than a healthy ageing educational programme (Pahor et al. 2006). Furthermore, in frail older people, 12 month combined training (aerobic, strength, balance and flexibility) was more effective than conventional aerobic training alone at improving general activity levels (Molino-Lova et al. 2013) and functional mobility (Fielding et al. 2007; Pahor et al. 2014), and reduced risk of mobility disability by around $30 \%$ (Pahor et al. 2014).

\section{Risks and adverse events}

The UK Department of Health (2011), US Department of Health (2009, 2011), American College of Sports Medicine (1998), World Health Organisation (2010) and European Association of Cardiovascular Prevention and Rehabilitation (Borjesson et al. 2011) guidelines state that exercise is generally safe for older people and they therefore need not consult a medical practitioner before increasing physical activity levels. Nevertheless, as cardiovascular risks, such as increased blood pressure, arrhythmia or myocardial infarction are concerns when taking up exercise, the European Association of Cardiovascular Prevention and Rehabilitation suggest self-assessment by a brief questionnaire (Borjesson et al. 2011) to determine the need for advice from health professionals. In most cases, this is precautionary and a medical practitioner will allow the person to proceed with moderate exercise. Training intensity or exercise duration should be increased modestly not more than once every 4 weeks (Huang et al. 2005).

Exercise classes to improve balance are not associated with increased risk of adverse events. However, more intense falls-prevention classes may have an increased risk of muscle soreness or swollen joints in sedentary people unaccustomed to exercise (Gillespie et al. 2012; Howe et al. 2007). Frail or sedentary older adults living in care may have a small increased risk of falls shortly after falls-prevention classes, possibly related to physical or mental fatigue, but there is no evidence of serious adverse outcomes, injury or cardiovascular events (Crocker et al. 2013). Exercise interventions to improve balance in those diagnosed with dementia bring numerous benefits without an increased risk of adverse outcomes (Forbes et al. 2013). 
Risks associated with resistance training have been reviewed in two reports (Liu and Latham 2009, 2010). The vast majority of clinical trials did not report any adverse events after exercise. It is not possible to know whether this was because no adverse events occurred or whether they were not reported. In trials that did report adverse events, the most common were minor musculoskeletal problems such as pain in joints, bruising or sprains. Less common were cardiovascular events, with only one occurrence out of the 58 reviewed trials that included people aged $>60$ years that did report any adverse events (Liu and Latham 2010). There was a higher risk of any adverse event in older people after intense exercise in those who already experienced pre-existing health problems, were functionally limited or were sedentary (Liu and Latham 2010).

Low and moderate intensity aerobic exercise are low risk for older people and even more intense aerobic activities carry relatively little risk. Several studies reported no greater risk of adverse events from moderate exercise compared with those not participating in physical activities (Church et al. 2007; Dunn et al. 1999; King et al. 2002). In a study of 1635 older people with moderate mobility impairments, a largescale mixed aerobic, resistance and balance exercise intervention reported a $8 \%$ higher incidence of serious adverse events compared with a (sedentary) health education programme (Pahor et al. 2014). An aerobic exercise intervention aiming for $60 \mathrm{~min}$ intense cycling/walking/running/rowing exercise 6 days per week over 12 months for previously sedentary men aged 40-75 years found no increased risk of injury or adverse event. In the non-exercise control group, $27 \%$ experienced an injury compared with $28 \%$ in the exercise group (Campbell et al. 2012).

Cardiovascular events during intense exercise have been estimated to occur at a rate of around 1 event per 100 years of vigorous activity (Powell et al. 2011). Risks tend to be highest during the first few weeks of a new vigorous training programme (Mann et al. 1969). However, for older people well-accustomed to intense exercise, participating in competitive vigorous sports does not carry higher risk compared with those faced by younger adults (Ganse et al. 2014). Extreme endurance running, such as a marathon, carried just $0.0005 \%$ risk of sudden cardiac arrest across the population of runners, including older runners, equivalent to around five incidents per one-million runners (Kim et al. 2012). Because exercise has many positive effects, the overall risk of adverse events (covering all activities in the day) was approximately halved in people who achieved $>140 \mathrm{~h}$ vigorous activity per week compared with sedentary people (Siscovick et al. 1984), demonstrating a clear net decrease in adverse events in healthy and active people compared with sedentary.

\section{Social, demographic and psychological considerations}

Exercise habits differ depending on income, gender, age, ethnicity and disability (Department of Health 2011). Older people in higher socioeconomic positions are more likely to maintain high levels of physical activity. Those in lower socioeconomic positions are more likely to remain inactive, to move from high levels of physical activity to low levels of physical activity, and to move from medium levels of physical activity to low levels (Matthews et al. 2014). These data support others showing clear social and demographic influences on exercise habits (Evans and Kantrowitz 2002; Evans and Kim 2010; Menec et al. 2010; Salas 2002). The progression towards physical disability and frailty increases after retirement (Iparraguirre 2014; Stenholm et al. 2014b) and evidence from the United States and Europe suggests that poverty (Wahrendorf et al. 2013) and underlying disease increase the risk of physical disability in a dose-response manner (Stenholm et al. 2014a). People from more affluent backgrounds are almost three times more likely to be healthy in older age (Hamer et al. 2014) compared with those from poorer communities and a strong relationship exists between socio-economic position and health in older age (physical, psychological and overall frailty) (Banks et al. 2006; Marmot et al. 2003). Although the strength of this relationship reduces with age, this appears to largely be a consequence of higher mortality rates amongst the most vulnerable in lower socioeconomic groups (McMunn et al. 2009). Indeed, longitudinal studies examining the onset of illness and/or mortality among older people who were initially healthy shows marked increases in risk with decrease in socioeconomic position (McMunn et al. 2009).

In addition to the social and demographic associations with healthy behaviours, psychological factors 
are also important. The internal motivations for sports participation amongst older people include the health, social, mental and emotional benefits that help to maintain physical independence (Sport-England 2006). External motivation comes from the media, doctors, partners, friends and/or family. Provision of local opportunities and an exercise 'buddy' also help. The most common barriers to exercise are costs, lack of time, and physical limitations. Other limiting factors included cultural 'norms', language barriers and the need for clothing that may be deemed inappropriate (Sport-England 2006). Older people felt that the best way to increase participation would be to keep costs low, make sessions enjoyable, be reassured about the safety of activities and the opportunities to be physically active could be better advertised (raise awareness of local exercise classes) (Sport-England 2006).

Other less modifiable individual factors can predict initiation and maintenance of physical activity. For instance, a better physical and mental health, cognitive functioning, lower age, and higher baseline physical activity are associated with maintenance of physical activities (Koeneman et al. 2011; van Stralen et al. 2010). Of the individual factors investigated, the most consistent predictor of physical activity (this differs from sports participation) initiation and long-term maintenance is self-efficacy (French 2013; Koeneman et al. 2011; van Stralen et al. 2010). Self-efficacy for physical activity can be thought of as the belief in one's capabilities to organize and execute that behaviour, or the belief that performing physical activity is under one's control and may be easy (Bandura 1997). It is possible to increase people's selfefficacy by asking them to successfully perform a behaviour in a safe environment, recalling successfully performing it before, or seeing others perform the behaviour (Darker et al. 2010; French et al. 2014). Another factor that is important in the initiation of physical activity is a person's expectations that the activities will result in positive outcomes (van Stralen et al. 2010). These expectations may relate to health, social or other desired outcomes. People who have more social goals may choose activities such as group walks, whereas those who are concerned about falling may choose more structured programmes that directly address balance. Importantly, where people are satisfied with the outcomes they originally desired, they are more likely to continue regular physical activity (Kassavou et al. 2014).

As people get older, they are less interested in improving their health, but more interested in retaining the health and capacities they already possess (Lockenhoff and Carstensen 2004). Given this, it is important for physical activity programmes to reassure potential participants that they are unlikely to incur injuries or otherwise harm themselves. Equally, rather than promoting physical activity programmes on the basis of health improvements, many people will be more interested in activities that they view as being intrinsically enjoyable, such as interactions with other people who are also performing the activities (Devereux-Fitzgerald et al. 2016). These group activities are likely to be satisfying and become habitual through repetition (Gardner 2013). Women tend to engage more with walking groups (Kassavou et al. 2013), while men may tend to value sports, especially if it relates to teams they support (Hunt et al. 2014). As well as these individual factors, participation in physical activity is more likely when significant others approve, when people have larger social networks and when social norms amongst their peers includes being physically active (Koeneman et al. 2011; van Stralen et al. 2010). Similarly, at the wider societal level, more people are likely to be physical activity when costs are low and a wide variety of physical activity opportunities are available (Sallis and Owen 1998). Finally, physical activity can be stimulated by features of the built environment, such as safe foot- or cycle-paths and parks, and societal norms and practices that contribute to increased physical activity (Sallis and Owen 1998).

\section{Conclusions}

The evidence shows that regular physical activity is safe for healthy and for frail older people and the risks of developing major cardiovascular and metabolic diseases, obesity, falls, cognitive impairments, osteoporosis and muscular weakness are decreased by regularly completing activities ranging from low intensity walking through to more vigorous sports and resistance exercises. Yet, participation in physical activities remains low amongst older adults, particularly those living in less affluent areas. Older people 
may be encouraged to increase their activities if influenced by clinicians, family or friends, keeping costs low and enjoyment high, facilitating groupbased activities and raising self-efficacy for exercise.

Open Access This article is distributed under the terms of the Creative Commons Attribution 4.0 International License (http:// creativecommons.org/licenses/by/4.0/), which permits unrestricted use, distribution, and reproduction in any medium, provided you give appropriate credit to the original author(s) and the source, provide a link to the Creative Commons license, and indicate if changes were made.

\section{References}

ACSM (1998) American College of Sports Medicine Position Stand. Exercise and physical activity for older adults Med Sci Sports Exerc 30:992-1008

Age UK (2010) Healthy ageing evidence review. http://www. ageuk.org.uk/Documents/EN-GB/For-Professionals/ Health-and-wellbeing/EvidenceReviewHealthyAgeing pdf?dtrk=true. Accessed 8 June 2015

Age UK (2015) A practical guide to healthy ageing. http://www. england.nhs.uk/wp-content/uploads/2015/01/pract-guidhlthy-age.pdf. Accessed 08 July 2015

Ashfield TA, Syddall HE, Martin HJ, Dennison EM, Cooper C, Aihie Sayer A (2010) Grip strength and cardiovascular drug use in older people: findings from the Hertfordshire cohort study. Age Ageing 39:185-191. doi:10.1093/ ageing/afp203

Bandura A (1997) Self-efficacy: the exercise of control. Freeman, New York

Banks J, Breeze E, Lessof C, Nazroo J (2006) Retirement, health and relationships of the older population in England: the 2004 English longitudinal study of ageing. The Institute for Fiscal Studies, London. ISBN 190327446 X

Bauer JM (2015) Effects of a vitamin D and leucine-enriched whey protein oral nutrition supplement on measures of sarcopenia in older adults. The PROVIDE study: a randomized, double-blind, placebo-controlled trial. J Am Med Dir Assoc 16(9):740-747

Beijersbergen CM, Granacher U, Vandervoort AA, DeVita P, Hortobagyi T (2013) The biomechanical mechanism of how strength and power training improves walking speed in old adults remains unknown. Ageing Res Rev 12:618-627. doi:10.1016/j.arr.2013.03.001

Berk DR, Hubert HB, Fries JF (2006) Associations of changes in exercise level with subsequent disability among seniors: a 16-year longitudinal study. J Gerontol Ser A 61:97-102

Bijlsma AY, Meskers CG, van den Eshof N, Westendorp RG, Sipila S, Stenroth L, Sillanpaa E, McPhee JS, Jones DA, Narici MV, Gapeyeva H, Paasuke M, Voit T, Barnouin Y, Hogrel JY, Butler-Browne G, Maier AB (2013a) Diagnostic criteria for sarcopenia and physical performance. Age. doi:10.1007/s11357-013-9556-5

Bijlsma AY, Meskers MC, Molendijk M, Westendorp RG, Sipila S, Stenroth L, Sillanpaa E, McPhee JS, Jones DA,
Narici M, Gapeyeva H, Paasuke M, Seppet E, Voit T, Barnouin Y, Hogrel JY, Butler-Browne G, Maier AB (2013b) Diagnostic measures for sarcopenia and bone mineral density. Osteoporos Int 24:2681-2691. doi:10. 1007/s00198-013-2376-8

Booth FW, Gordon SE, Carlson CJ, Hamilton MT (2000) Waging war on modern chronic diseases: primary prevention through exercise biology. J Appl Physiol 88:774-787

Borjesson M, Urhausen A, Kouidi E, Dugmore D, Sharma S, Halle M, Heidbuchel H, Bjornstad HH, Gielen S, Mezzani A, Corrado D, Pelliccia A, Vanhees L (2011) Cardiovascular evaluation of middle-aged/senior individuals engaged in leisure-time sport activities: position stand from the sections of exercise physiology and sports cardiology of the European Association of Cardiovascular Prevention and Rehabilitation. Eur J Cardiovasc Prev Rehabil 18:446-458. doi:10.1097/HJR.0b013e32833bo969

British Geriatric Society (2014) Fit for frailty: consensus best practice guidance for the care of older people living with frailty in community and outpatient settings. http://www. bgs.org.uk/campaigns/fff/fff_full.pdf. Accessed Feb 2016

Bruce B, Fries JF, Hubert H (2008) Regular vigorous physical activity and disability development in healthy overweight and normal-weight seniors: a 13-year study. Am J Public Health 98:1294-1299. doi:10.2105/AJPH.2007.119909

Buchner DM, Cress ME, de Lateur BJ, Esselman PC, Margherita AJ, Price R, Wagner EH (1997) The effect of strength and endurance training on gait, balance, fall risk, and health services use in community-living older adults. J Gerontol Ser A 52:M218-M224

Campbell MJ, McComas AJ, Petito F (1973) Physiological changes in ageing muscles. J Neurol Neurosurg Psychiatry 36:174-182

Campbell K, Foster-Schubert K, Xiao L, Alfano C, Bertram LC, Duggan C, Irwin M, McTiernan A (2012) Injuries in sedentary individuals enrolled in a 12-month, randomized, controlled, exercise trial. J Phys Act Health 9:198-207

Chin APMJ, van Poppel MN, Twisk JW, van Mechelen W (2004) Effects of resistance and all-round, functional training on quality of life, vitality and depression of older adults living in long-term care facilities: a 'randomized' controlled trial [ISRCTN87177281]. BMC Geriatr 4:5. doi:10.1186/1471-2318-4-5

Chin APMJ, van Poppel MN, van Mechelen W (2006) Effects of resistance and functional-skills training on habitual activity and constipation among older adults living in long-term care facilities: a randomized controlled trial. BMC Geriatr 6:9. doi:10.1186/1471-2318-6-9

Chou WT, Tomata Y, Watanabe T, Sugawara Y, Kakizaki M, Tsuji I (2014) Relationships between changes in time spent walking since middle age and incident functional disability. Prev Med 59:68-72. doi:10.1016/j.ypmed.2013.11.019

Church TS, Earnest CP, Skinner JS, Blair SN (2007) Effects of different doses of physical activity on cardiorespiratory fitness among sedentary, overweight or obese postmenopausal women with elevated blood pressure: a randomized controlled trial. JAMA 297:2081-2091. doi:10. 1001/jama.297.19.2081

Clark DO (1996) The effect of walking on lower body disability among older blacks and whites. Am J Public Health $86: 57-61$ 
Clegg A, Young J, Iliffe S, Rikkert MO, Rockwood K (2013) Frailty in elderly people. Lancet 381:752-762. doi:10. 1016/S0140-6736(12)62167-9

Crocker T, Forster A, Young J, Brown L, Ozer S, Smith J, Green J, Hardy J, Burns E, Glidewell E, Greenwood DC (2013) Physical rehabilitation for older people in long-term care. Cochrane Database Syst Rev 2:CD004294. doi:10.1002/ 14651858.CD004294.pub3

Daniels R, van Rossum E, de Witte L, Kempen GI, van den Heuvel W (2008) Interventions to prevent disability in frail community-dwelling elderly: a systematic review. BMC Health Serv Res 8:278

Darker CD, French DP, Eves FF, Sniehotta FF (2010) An intervention to promote walking amongst the general population based on an 'extended' theory of planned behaviour: a waiting list randomised controlled trial. Psychol Health 25:71-88. doi:10.1080/08870440902893716

Davidson LE, Hudson R, Kilpatrick K, Kuk JL, McMillan K, Janiszewski PM, Lee S, Lam M, Ross R (2009) Effects of exercise modality on insulin resistance and functional limitation in older adults: a randomized controlled trial. Arch Intern Med 169:122-131. doi:10.1001/archinternmed.2008. 558

Degens H, Maden-Wilkinson TM, Ireland A, Korhonen MT, Suominen H, Heinonen A, Radak Z, McPhee JS, Rittweger J (2013a) Relationship between ventilatory function and age in master athletes and a sedentary reference population. Age 35:1007-1015. doi:10.1007/s11357-012-9409-7

Degens H, Rittweger J, Parviainen T, Timonen KL, Suominen H, Heinonen A, Korhonen MT (2013b) Diffusion capacity of the lung in young and old endurance athletes. Int J Sports Med 34:1051-1057. doi:10.1055/s-0033-1345137

Department for Culture MaS (2011) Adult participation in sport: analysis of the taking part survey. https://www.gov.uk/ government/uploads/system/uploads/attachment_data/file/ 137986/tp-adult-participation-sport-analysis.pdf. Accessed 10 July 2015

Department of Health UK (2011) Start active, stay active: UK Physical Activity Guidelines. Department of Health, UK http://www.dh.gov.uk/health/category/publications/

Devereux-Fitzgerald A, Powell R, Dewhurst A, French D (2016) The acceptability of physical activity interventions to older adults: a systematic review and meta-synthesis. Soc Sci Med (in press)

Dufour AB, Hannan MT, Murabito JM, Kiel DP, McLean RR (2013) Sarcopenia definitions considering body size and fat mass are associated with mobility limitations: the Framingham study. J Gerontol Ser A 68:168-174. doi:10.1093/ gerona/gls 109

Dunn AL, Marcus BH, Kampert JB, Garcia ME, Kohl HW 3rd, Blair SN (1999) Comparison of lifestyle and structured interventions to increase physical activity and cardiorespiratory fitness: a randomized trial. JAMA 281:327-334

Earnest CP, Johannsen NM, Swift DL, Lavie CJ, Blair SN, Church TS (2013) Dose effect of cardiorespiratory exercise on metabolic syndrome in postmenopausal women. Am J Cardiol 111:1805-1811. doi:10.1016/j.amjcard.2013.02.037

Ebrahim S, Wannamethee SG, Whincup P, Walker M, Shaper AG (2000) Locomotor disability in a cohort of British men: the impact of lifestyle and disease. Int $\mathrm{J}$ Epidemiol 29:478-486
Eurostat (2014) Projected old-age dependency ratio (tsdde511) Eurostat (2015) Deaths and life expectancy data. http://eceuropaeu/ eurostat/web/population-demography-migration-projections/ deaths-life-expectancy-data. Accessed 15 Feb 2016

Evans GW, Kantrowitz E (2002) Socioeconomic status and health: the potential role of environmental risk exposure. Annu Rev Public Health 23:303-331. doi:10.1146/ annurev.publhealth.23.112001.112349

Evans GW, Kim P (2010) Multiple risk exposure as a potential explanatory mechanism for the socioeconomic statushealth gradient. Ann N Y Acad Sci 1186:174-189. doi:10. 1111/j.1749-6632.2009.05336.x

Feldman DI, Al-Mallah MH, Keteyian SJ, Brawner CA, Feldman T, Blumenthal RS, Blaha MJ (2015) No evidence of an upper threshold for mortality benefit at high levels of cardiorespiratory fitness. J Am Coll Cardiol 65:629-630. doi:10.1016/j.jacc.2014.11.030

Ferrucci L, Izmirlian G, Leveille S, Phillips CL, Corti MC, Brock DB, Guralnik JM (1999) Smoking, physical activity, and active life expectancy. Am J Epidemiol 149:645-653

Fiatarone MA, Marks EC, Ryan ND, Meredith CN, Lipsitz LA, Evans WJ (1990) High-intensity strength training in nonagenarians. Effects on skeletal muscle. JAMA 263:3029-3034

Fielding RA, Katula J, Miller ME, Abbott-Pillola K, Jordan A, Glynn NW, Goodpaster B, Walkup MP, King AC, Rejeski WJ (2007) Activity adherence and physical function in older adults with functional limitations. Med Sci Sports Exerc 39:1997-2004. doi:10.1249/mss. 0b013e318145348d

Forbes D, Thiessen EJ, Blake CM, Forbes SC, Forbes S (2013) Exercise programs for people with dementia. Cochrane Database Syst Rev 12:CD006489. doi:10.1002/14651858. CD006489.pub3

Forster A, Lambley R, Young JB (2010) Is physical rehabilitation for older people in long-term care effective? Findings from a systematic review. Age Ageing 39:169-175. doi:10.1093/ageing/afp247

Franco MR, Pereira LS, Ferreira PH (2014) Exercise interventions for preventing falls in older people living in the community. Br J Sports Med 48:867-868. doi:10.1136/ bjsports-2012-092065

French DP (2013) The role of self-efficacy in changing healthrelated behaviour: cause, effect or spurious association? $\mathrm{Br}$ J Health Psychol 18:237-243. doi:10.1111/bjhp.12038

French DP, Olander EK, Chisholm A, Mc Sharry J (2014) Which behaviour change techniques are most effective at increasing older adults' self-efficacy and physical activity behaviour? A systematic review. Ann Behav Med 48:225-234. doi:10.1007/s12160-014-9593-Z

Fried LP, Tangen CM, Walston J, Newman AB, Hirsch C, Gottdiener J, Seeman T, Tracy R, Kop WJ, Burke G, McBurnie MA (2001) Frailty in older adults: evidence for a phenotype. J Gerontol Ser A 56:M146-M156

Ganse B, Degens H, Drey M, Korhonen MT, McPhee J, Muller K, Johannes BW, Rittweger J (2014) Impact of age, performance and athletic event on injury rates in master athletics - first results from an ongoing prospective study. J Musculoskelet Neuron Interactions 14:148-154

Ganz DA, Bao Y, Shekelle PG, Rubenstein LZ (2007) Will my patient fall? JAMA 297:77-86. doi:10.1001/jama.297.1.77 
Gardner B (2013) Promoting habit formation. Health Psychol Rev 7(supplement):137-158

Gill TM, Allore HG, Hardy SE, Guo Z (2006) The dynamic nature of mobility disability in older persons. J Am Geriatr Soc 54:248-254. doi:10.1111/j.1532-5415.2005.00586.x

Gillespie LD, Robertson MC, Gillespie WJ, Sherrington C, Gates S, Clemson LM, Lamb SE (2012) Interventions for preventing falls in older people living in the community. Cochrane Database Syst Rev 9:CD007146. doi:10.1002/ 14651858.CD007146.pub3

Hamer M, Lavoie KL, Bacon SL (2014) Taking up physical activity in later life and healthy ageing: the English longitudinal study of ageing. Br J Sports Med 48:239-243. doi:10.1136/bjsports-2013-092993

Hardy SE, Gill TM (2004) Recovery from disability among community-dwelling older persons. JAMA 291:15961602. doi:10.1001/jama.291.13.1596

Harridge SD, Kryger A, Stensgaard A (1999) Knee extensor strength, activation, and size in very elderly people following strength training. Muscle Nerve 22:831-839

Health USDo (2009) Physical Activity Guidelines Advisory Committee report, 2008. To the Secretary of Health and Human Services Part A: executive summary. Nutr Rev 67:114-120. doi:10.1111/j.1753-4887.2008.00136.x

Healy GN, Dunstan DW, Salmon J, Cerin E, Shaw JE, Zimmet PZ, Owen N (2008) Breaks in sedentary time: beneficial associations with metabolic risk. Diabetes Care 31:661-666. doi:10.2337/dc07-2046

Holviala J, Kraemer WJ, Sillanpaa E, Karppinen H, Avela J, Kauhanen A, Hakkinen A, Hakkinen K (2012) Effects of strength, endurance and combined training on muscle strength, walking speed and dynamic balance in aging men. Eur J Appl Physiol 112:1335-1347. doi:10.1007/s00421011-2089-7

Howe TE, Rochester L, Jackson A, Banks PM, Blair VA (2007) Exercise for improving balance in older people. Cochrane Database Syst Rev. doi:10.1002/14651858.CD004963. pub2

Huang G, Gibson CA, Tran ZV, Osness WH (2005) Controlled endurance exercise training and $\mathrm{VO} 2 \mathrm{max}$ changes in older adults: a meta-analysis. Prev Cardiol 8:217-225

Hunt K, Wyke S, Gray CM, Anderson AS, Brady A, Bunn C, Donnan PT, Fenwick E, Grieve E, Leishman J, Miller E, Mutrie N, Rauchhaus P, White A, Treweek S (2014) A gender-sensitised weight loss and healthy living programme for overweight and obese men delivered by Scottish Premier League football clubs (FFIT): a pragmatic randomised controlled trial. Lancet 383:1211-1221. doi:10.1016/S0140-6736(13)62420-4

Iparraguirre J (2014) Physical Functioning in work and retirement: commentary on age-related trajectories of physical functioning in work and retirement -the role of sociodemographic factors, lifestyle and disease by Stenholm et al. J Epidemiol Commun Health 68:493-499. doi:10.1136/ jech-2014-203945

Ireland A, Maden-Wilkinson T, Ganse B, Degens H, Rittweger J (2014) Effects of age and starting age upon side asymmetry in the arms of veteran tennis players: a cross-sectional study. Osteoporos Int 25:1389-1400. doi:10.1007/s00198-014-2617-5
Jones CJ, Rikli RE, Beam WC (1999) A 30-s chair-stand test as a measure of lower body strength in community-residing older adults. Res Quart Exerc Sport 70:113-119. doi:10. 1080/02701367.1999.10608028

Kassavou A, Turner A, French DP (2013) Do interventions to promote walking in groups increase physical activity? A meta-analysis. Int J Behav Nutr Phys Act 10:18. doi:10. 1186/1479-5868-10-18

Kassavou A, Turner A, Hamborg T, French DP (2014) Predicting maintenance of attendance at walking groups: testing constructs from three leading maintenance theories. Health Psychol 33:752-756. doi:10.1037/hea0000015

Kim JH, Malhotra R, Chiampas G, d'Hemecourt P, Troyanos C, Cianca J, Smith RN, Wang TJ, Roberts WO, Thompson PD, Baggish AL (2012) Cardiac arrest during long-distance running races. N Engl J Med 366:130-140. doi:10. 1056/NEJMoa1106468

Kim LG, Adamson J, Ebrahim S (2013) Influence of life-style choices on locomotor disability, arthritis and cardiovascular disease in older women: prospective cohort study. Age Ageing 42:696-701. doi:10.1093/ageing/aft127

King AC, Baumann K, O'Sullivan P, Wilcox S, Castro C (2002) Effects of moderate-intensity exercise on physiological, behavioral, and emotional responses to family caregiving: a randomized controlled trial. J Gerontol Ser A 57:M26M36

Koeneman MA, Verheijden MW, Chinapaw MJ, Hopman-Rock M (2011) Determinants of physical activity and exercise in healthy older adults: a systematic review. Int J Behav Nutr Phys Act 8:142. doi:10.1186/1479-5868-8-142

Lautenschlager NT, Cox KL, Flicker L, Foster JK, van Bockxmeer FM, Xiao J, Greenop KR, Almeida OP (2008) Effect of physical activity on cognitive function in older adults at risk for Alzheimer disease: a randomized trial. J Am Med Assoc 300:1027-1037. doi:10.1001/jama.300.9.1027

Lee IM, Shiroma EJ, Lobelo F, Puska P, Blair SN, Katzmarzyk PT (2012) Effect of physical inactivity on major noncommunicable diseases worldwide: an analysis of burden of disease and life expectancy. Lancet 380:219-229. doi:10.1016/S0140-6736(12)61031-9

Lexell J, Taylor CC, Sjostrom M (1988) What is the cause of the ageing atrophy? Total number, size and proportion of different fiber types studied in whole vastus lateralis muscle from 15- to 83-year-old men. J Neurol Sci 84:275-294

Liu CJ, Latham NK (2009) Progressive resistance strength training for improving physical function in older adults. Cochrane Database Syst Rev. doi:10.1002/14651858. CD002759.pub2

Liu CJ, Latham N (2010) Adverse events reported in progressive resistance strength training trials in older adults: 2 sides of a coin. Arch Phys Med Rehabil 91:1471-1473. doi:10.1016/ j.apmr.2010.06.001

Lockenhoff CE, Carstensen LL (2004) Socioemotional selectivity theory, aging, and health: the increasingly delicate balance between regulating emotions and making tough choices. J Pers 72:1395-1424. doi:10.1111/j.1467-6494. 2004.00301.x

Maden-Wilkinson TM, McPhee JS, Rittweger J, Jones DA, Degens H (2013) Thigh muscle volume in relation to age, sex and femur volume. Age. doi:10.1007/s11357-013-9571-6 
Maden-Wilkinson TM, McPhee JS, Jones DA, Degens H (2014) Age related loss of muscle mass, Strength and power and their association with mobility in recreationally active UK older adults. J Aging Phys Act. doi:10.1123/japa.20130219

Manini TM, Everhart JE, Patel KV, Schoeller DA, Colbert LH, Visser M, Tylavsky F, Bauer DC, Goodpaster BH, Harris TB (2006) Daily activity energy expenditure and mortality among older adults. J Am Med Assoc 296:171-179. doi:10. 1001/jama.296.2.171

Mann GV, Garrett HL, Farhi A, Murray H, Billings FT (1969) Exercise to prevent coronary heart disease. An experimental study of the effects of training on risk factors for coronary disease in men. Am J Med 46:12-27

Marengoni A, Angleman S, Melis R, Mangialasche F, Karp A, Garmen A, Meinow B, Fratiglioni L (2011) Aging with multimorbidity: a systematic review of the literature. Ageing Res Rev 10:430-439. doi:10.1016/j.arr.2011.03. 003

Marmot M, Banks J, Blundell R, Lessof C, Nazroo J (2003) Health, wealth and lifestyles of the older population in England: the 2002 English longitudinal study of ageing. The Institute for Fiscal Studies, London. ISBN 1903274346

Matthews K, Demakakos P, Nazroo J, Shankar A (2014) The evolution of lifestyles in older age in England. In:, Banks J, Nazroo J, Steptoe A (eds) The dynamics of ageing: evidence from the English longitudinal study of ageing 2002-2012. The Institute for Fiscal Studies, London. ISBN 978-1-909463-58-5, 51-93

McMunn A, Nazroo J, Breeze E (2009) Inequalities in health at older ages: a longitudinal investigation of the onset of illness and survival effects in England. Age Ageing 38:181-187. doi:10.1093/ageing/afn236

McPhee JS, Hogrel JY, Maier AB, Seppet E, Seynnes OR, Sipila S, Bottinelli R, Barnouin Y, Bijlsma AY, Gapeyeva H, Maden-Wilkinson TM, Meskers CG, Paasuke M, Sillanpaa E, Stenroth L, Butler-Browne G, Narici MV, Jones DA (2013) Physiological and functional evaluation of healthy young and older men and women: design of the European MyoAge study. Biogerontology 14:325-337. doi:10.1007/ s10522-013-9434-7

Menec VH, Shooshtari S, Nowicki S, Fournier S (2010) Does the relationship between neighborhood socioeconomic status and health outcomes persist into very old age? A population-based study. J Aging Health 22:27-47. doi:10. 1177/0898264309349029

Michaelis I, Kwiet A, Gast U, Boshof A, Antvorskov T, Jung T, Rittweger J, Felsenberg D (2008) Decline of specific peak jumping power with age in master runners. J Musculoskelet Neuron Interactions 8:64-70

Molino-Lova R, Pasquini G, Vannetti F, Paperini A, Forconi T, Polcaro P, Zipoli R, Cecchi F, Macchi C (2013) Effects of a structured physical activity intervention on measures of physical performance in frail elderly patients after cardiac rehabilitation: a pilot study with 1-year follow-up. Intern Emerg Med 8:581-589. doi:10.1007/s11739-011-0654-z

Nazroo J, Zaninotto P, Gjonça E (2008) Mortality and healthy life expectancy. In: Banks J, Breeze E, Lessof C, Nazroo J (eds) Living in the 21st century: older people in England.
The 2006 English longitudinal study of ageing. The Institute for Fiscal Studies, London, pp 253-288

NICE (2009) Rehabilitation after critical illness: NICE guideline National Institute for Health and Clinical Excellence. http://guidance.nice.org.uk/CG83/Guidance/pdf/English

ONS (2013) General health (General lifestyle survey overview-a report on the 2011 general lifestyle survey) Office for National Statistics (UK). http://www.ons.gov.uk/ons/ dcp171776_302351.pdf. Accessed 17 Sep 2014

Orr R, de Vos NJ, Singh NA, Ross DA, Stavrinos TM, Fiatarone-Singh MA (2006) Power training improves balance in healthy older adults. J Gerontol Ser A 61:78-85

Pahor M, Blair SN, Espeland M, Fielding R, Gill TM, Guralnik JM, Hadley EC, King AC, Kritchevsky SB, Maraldi C, Miller ME, Newman AB, Rejeski WJ, Romashkan S, Studenski S (2006) Effects of a physical activity intervention on measures of physical performance: results of the lifestyle interventions and independence for Elders Pilot (LIFE-P) study. J Gerontol Ser A $61: 1157-1165$

Pahor M, Guralnik JM, Ambrosius WT, Blair S, Bonds DE, Church TS, Espeland MA, Fielding RA, Gill TM, Groess1 EJ, King AC, Kritchevsky SB, Manini TM, McDermott MM, Miller ME, Newman AB, Rejeski WJ, Sink KM, Williamson JD (2014) Effect of structured physical activity on prevention of major mobility disability in older adults: the LIFE study randomized clinical trial. JAMA 311:2387-2396. doi:10.1001/jama.2014.5616

Paterson DH, Warburton DE (2010) Physical activity and functional limitations in older adults: a systematic review related to Canada's physical activity guidelines. Int J Behav Nutr Phys Act 7:38. doi:10.1186/1479-5868-7-38

Pearson SJ, Young A, Macaluso A, Devito G, Nimmo MA, Cobbold M, Harridge SD (2002) Muscle function in elite master weightlifters. Med Sci Sports Exerc 34:1199-1206

Pereira A, Izquierdo M, Silva AJ, Costa AM, Bastos E, Gonzalez-Badillo JJ, Marques MC (2012) Effects of highspeed power training on functional capacity and muscle performance in older women. Exp Gerontol 47:250-255. doi:10.1016/j.exger.2011.12.010

Piasecki M, Ireland A, Jones DA, McPhee JS (2015a) Agedependent motor unit remodelling in human limb muscles. Biogerontology. doi:10.1007/s10522-015-9627-3

Piasecki M, Ireland A, Stashuk D, Hamilton-Wright A, Jones DA, McPhee JS (2015b) Age-related neuromuscular changes affecting human vastus lateralis. J Physiol. doi:10. 1113/JP271087

Powell KE, Paluch AE, Blair SN (2011) Physical activity for health: what kind? How much? How intense? On top of what? Annu Rev Public Health 32:349-365. doi:10.1146/ annurev-publhealth-031210-101151

Power GA, Dalton BH, Behm DG, Vandervoort AA, Doherty TJ, Rice CL (2010) Motor unit number estimates in masters runners: use it or lose it? Med Sci Sports Exerc 42:16441650. doi:10.1249/MSS.0b013e3181d6f9e9

Power GA, Dalton BH, Behm DG, Doherty TJ, Vandervoort AA, Rice CL (2012) Motor unit survival in life-long runners is muscle-dependent. Med Sci Sports Exerc. doi:10. 1249/MSS1240b1013e318249953c 
Rechel B, Grundy E, Robine JM, Cylus J, Mackenbach JP, Knai C, McKee M (2013) Ageing in the European Union. Lancet 381:1312-1322. doi:10.1016/S0140-6736(12)62087-X

Rikli R, Jones C (1998) The reliability and validity of a 6-min walk test as a measure of physical endurance in older adults. J Ageing Phys Act 6:363-375

Rittweger J, di Prampero PE, Maffulli N, Narici MV (2009) Sprint and endurance power and ageing: an analysis of master athletic world records. Proc Biol Sci 276:683-689. doi:10.1098/rspb.2008.1319

Roberts CK, Hevener AL, Barnard RJ (2013) Metabolic syndrome and insulin resistance: underlying causes and modification by exercise training. Compr Physiol 3:1-58. doi:10.1002/cphy.c110062

Rockwood K, Song X, MacKnight C, Bergman H, Hogan DB, McDowell I, Mitnitski A (2005) A global clinical measure of fitness and frailty in elderly people. Can Med Assoc J 173:489-495. doi:10.1503/cmaj.050051

Roh KH, Park HA (2013) A meta-analysis of the effect of walking exercise on lower limb muscle endurance, whole body endurance and upper body flexibility in elders. J Korean Acad Nurs 43:536-546. doi:10.4040/jkan.2013. 43.4.536

Rosenberg IH (1997) Sarcopenia: origins and clinical relevance. J Nutr 127:990S-991S

Rubenstein LZ, Josephson KR, Trueblood PR, Loy S, Harker JO, Pietruszka FM, Robbins AS (2000) Effects of a group exercise program on strength, mobility, and falls among fall-prone elderly men. J Gerontol Ser A 55:M317-M321

Runge M, Rittweger J, Russo CR, Schiessl H, Felsenberg D (2004) Is muscle power output a key factor in the agerelated decline in physical performance? a comparison of muscle cross section, chair-rising test and jumping power. Clin Physiol Funct Imaging 24(6):335-340

Sabia S, Singh-Manoux A, Hagger-Johnson G, Cambois E, Brunner EJ, Kivimaki M (2012) Influence of individual and combined healthy behaviours on successful aging. Can Med Assoc J 184:1985-1992. doi:10.1503/cmaj.121080

Salas C (2002) On the empirical association between poor health and low socioeconomic status at old age. Health Econ 11:207-220

Sallinen J, Stenholm S, Rantanen T, Heliovaara M, Sainio P, Koskinen S (2010) Hand-grip strength cut points to screen older persons at risk for mobility limitation. J Am Geriatr Soc 58(9):1721-1726

Sallis J, Owen N (1998) Physical activity and behavioral medicine. Sage, Thousand Oaks

Sillanpaa E, Hakkinen A, Nyman K, Mattila M, Cheng S, Karavirta L, Laaksonen DE, Huuhka N, Kraemer WJ, Hakkinen K (2008) Body composition and fitness during strength and/or endurance training in older men. Med Sci Sports Exerc 40:950-958. doi:10.1249/MSS. 0b013e318165c854

Sillanpaa E, Hakkinen K, Holviala J, Hakkinen A (2012) Combined strength and endurance training improves health-related quality of life in healthy middle-aged and older adults. Int J Sports Med 33:981-986. doi:10.1055/s0032-1311589

Sillanpaa E, Stenroth L, Bijlsma AY, Rantanen T, McPhee JS, Maden-Wilkinson TM, Jones DA, Narici MV, Gapeyeva H, Paasuke M, Barnouin Y, Hogrel JY, Butler-Browne GS,
Meskers CG, Maier AB, Tormakangas T, Sipila S (2014) Associations between muscle strength, spirometric pulmonary function and mobility in healthy older adults. Age 36:9667. doi:10.1007/s11357-014-9667-7

Siscovick DS, Weiss NS, Fletcher RH, Lasky T (1984) The incidence of primary cardiac arrest during vigorous exercise. N Engl J Med 311:874-877. doi:10.1056/ NEJM198410043111402

Sport-England (2006) Understanding participation in sport: what determines sports participation among recently retired people? http://www.sportengland.org/media/ 39497/understanding-participation-among-recentlyretired-people.pdf. Accessed 29 Sept 2014

Steib S, Schoene D, Pfeifer K (2010) Dose-response relationship of resistance training in older adults: a meta-analysis. Med Sci Sports Exerc 42:902-914. doi:10.1249/MSS. 0b013e3181c34465

Stenholm S, Westerlund H, Head J, Hyde M, Kawachi I, Pentti J, Kivimaki M, Vahtera J (2014a) Comorbidity and functional trajectories from midlife to old age: the health and retirement study. J Gerontol Ser A. doi:10.1093/gerona/ glu113

Stenholm S, Westerlund H, Salo P, Hyde M, Pentti J, Head J, Kivimaki M, Vahtera J (2014b) Age-related trajectories of physical functioning in work and retirement: the role of sociodemographic factors, lifestyle and disease. J Epidemiol Commun Health 68:503-509. doi:10.1136/jech2013-203555

Stenroth L, Sillanpaa E, McPhee JS, Narici MV, Gapeyeva H, Paasuke M, Barnouin Y, Hogrel JY, Butler-Browne G, Bijlsma A, Meskers CG, Maier AB, Finni T, Sipila S (2015) Plantarflexor muscle-tendon properties are associated with mobility in healthy older adults. J Gerontol Ser A. doi:10.1093/gerona/glv011

Stessman J, Hammerman-Rozenberg R, Cohen A, Ein-Mor E, Jacobs JM (2009) Physical activity, function, and longevity among the very old. Arch Intern Med 169:1476-1483. doi:10.1001/archinternmed.2009.248

Stewart KJ, Bacher AC, Turner K, Lim JG, Hees PS, Shapiro EP, Tayback M, Ouyang P (2005) Exercise and risk factors associated with metabolic syndrome in older adults. Am J Prev Med 28:9-18. doi:10.1016/j.amepre.2004.09.006

Sun Q, Townsend MK, Okereke OI, Franco OH, Hu FB, Grodstein F (2010) Physical activity at midlife in relation to successful survival in women at age 70 years or older. Arch Intern Med 170:194-201. doi:10.1001/ archinternmed.2009.503

Swain DP, Franklin BA (2006) Comparison of cardioprotective benefits of vigorous versus moderate intensity aerobic exercise. Am J Cardiol 97:141-147. doi:10.1016/j. amjcard.2005.07.130

Syddall H, Roberts HC, Evandrou M, Cooper C, Bergman H, Aihie Sayer A (2010) Prevalence and correlates of frailty among community-dwelling older men and women: findings from the Hertfordshire Cohort Study. Age Ageing 39:197-203. doi:10.1093/ageing/afp204

Tak E, Kuiper R, Chorus A, Hopman-Rock M (2013) Prevention of onset and progression of basic ADL disability by physical activity in community dwelling older adults: a meta-analysis. Ageing Res Rev 12:329-338. doi:10.1016/j. arr.2012.10.001 
Trappe S, Hayes E, Galpin A, Kaminsky L, Jemiolo B, Fink W, Trappe T, Jansson A, Gustafsson T, Tesch P (2013) New records in aerobic power among octogenarian lifelong endurance athletes. J Appl Physiol 114:3-10. doi:10.1152/ japplphysiol.01107.2012

van Stralen MM, Lechner L, Mudde AN, de Vries H, Bolman C (2010) Determinants of awareness, initiation and maintenance of physical activity among the over-fifties: a Delphi study. Health Educ Res 25:233-247. doi:10.1093/her/ cyn045

Wahrendorf M, Reinhardt JD, Siegrist J (2013) Relationships of disability with age among adults aged 50 to 85 : evidence from the United States, England and continental Europe. PLoS ONE 8:e71893. doi:10.1371/journal.pone.0071893

Wang BW, Ramey DR, Schettler JD, Hubert HB, Fries JF (2002) Postponed development of disability in elderly runners: a 13-year longitudinal study. Arch Intern Med 162:2285-2294

Wannamethee SG, Ebrahim S, Papacosta O, Shaper AG (2005) From a postal questionnaire of older men, healthy lifestyle factors reduced the onset of and may have increased recovery from mobility limitation. $\mathrm{J}$ Clin Epidemiol 58:831-840. doi:10.1016/j.jclinepi.2005.01.007
Weening-Dijksterhuis E, de Greef MH, Scherder EJ, Slaets JP, van der Schans CP (2011) Frail institutionalized older persons: a comprehensive review on physical exercise, physical fitness, activities of daily living, and quality-oflife. Am J Phys Med Rehabil 90:156-168. doi:10.1097/ PHM.0b013e3181f703ef

WHO (2010) Global recommendations on physical activity for health World Health Organisation. http://www.who.int/ dietphysicalactivity/factsheet_recommendations/en/

Wilks DC, Winwood K, Gilliver SF, Kwiet A, Chatfield M, Michaelis I, Sun LW, Ferretti JL, Sargeant AJ, Felsenberg D, Rittweger J (2009) Bone mass and geometry of the tibia and the radius of master sprinters, middle and long distance runners, race-walkers and sedentary control participants: a pQCT study. Bone 45:91-97. doi:10.1016/j.bone.2009.03. 660

Yao X, Hamilton RG, Weng NP, Xue QL, Bream JH, Li H, Tian J, Yeh SH, Resnick B, Xu X, Walston J, Fried LP, Leng SX (2011) Frailty is associated with impairment of vaccineinduced antibody response and increase in post-vaccination influenza infection in community-dwelling older adults. Vaccine 29:5015-5021. doi:10.1016/j.vaccine.2011.04. 077 